\title{
The Negative Impact of Social Media on People's Lives
}

\author{
Huizhong Pang \\ College of Letters and Science,The University of California, Los Angeles (UCLA), 405 Hilgard Ave, Los Angeles, CA \\ 90095 \\ Email: violethong0222@gmail.com
}

\begin{abstract}
Social media has brought many changes to people's lives. The negative impact of social media on people is reflected in all aspects of life, social and emotional, while social media brings convenience to life, it also brings emotional pressure to people. Since social networks are developing rapidly, various social media that attract people are constantly appearing, and people's addiction to social media is becoming more and more serious, it is urgent and important to study the negative aspects of social media. In this paper, we discuss the negative effects of social media on people through literature analysis and case studies to draw attention to them. Social media has brought people the pressure to constantly check new news, the anxiety caused by comparison, and the depression caused by online violence. A long time obsessed with social media will lead people into self-isolation, creating social barriers, and obsessing with a false sense of security on the Internet. Not only will young people be affected, but children will also be affected in this way, and even more because the information on the Internet is chaotic.
\end{abstract}

Keywords: Social media, Anxiety, Social distancing, Social disorders, Negative emotions, Internet violence

\section{INTRODUCTION}

There are many existing studies on the emergence and development of social media, its applications and implications, and its positive and negative effects, but this paper will discuss the effects on people's lives, emotions and children. Social media can bring happiness to people, and sharing life with others can bring satisfaction. Some people spend a lot of time thinking about obtaining this "satisfaction." For example, TIK TOK has become a popular culture in countries all over the world. Many people have received a lot of attention and likes by sharing their lives. Without social media, these are impossible to achieve. We must admit that social networks can help us maintain relationships and meet social needs. With the development and popularization of social media, both teenagers and children will be affected. Many people read a lot of social media content to escape the pressure of real-life when they work and study. Many people will waste a few when picking up their mobile phones before going to bed, which will seriously take up their sleep time and make them unable to concentrate on work the next day. These are the negative effects of social media addiction. This article will discuss the effects of social media on people and find out the emotional and life effects of social media on people. This article is based on a literature analysis and case studies of people's emotional and social disorders caused by social media, cyber violence due to social media, and the negative effects on children's development.

Society and people need to pay more attention to the negative effects of social media, whether it's reducing the anxiety and social disorders of being controlled by social media, the stress of online violence, or even misdirection for children's development. An early return to normal socialization, rebuilding social competence and protecting children's health information intake are all necessary and urgent.

\section{NEGATIVE EFFECTS OF SOCIAL MEDIA ON PEOPLE'S LIVES}

\subsection{Causes Anxiety and Social Disorders}

According to Tarafdar, Monideepa's statistics and research in "Explaining the Link between Technostress and Technology Addiction for Social Networking Sites: A Study of 'Distraction As a Coping Behavior.": Users can find that they are both a source of stress and a good place to spread stress. Even if users are under pressure when using SNS (social networking sites), they will use the same platform to cope with this pressure, transfer 
their other activities on SNS, and eventually build compulsive and excessive behaviors. As a result, they embed themselves in the social network environment instead of staying away from it, and form an addiction[1]. The emergence of new news on social media is rapid, causing people to fear being abandoned by society for not checking it in time, or being isolated and abandoned because they have no topic with friends. This fear of missing something is defined as FOMO (Fear of missing out) on the Internet. FOMO can cause serious anxiety.

\section{Profiles of social media news consumers in the U.S.}

$\%$ of each social media site's news consumers who are ...

\begin{tabular}{|c|c|c|c|c|c|c|c|}
\hline & Facebook & YouTube & Twitter & Instagram & LinkedIn & Snapchat & Reddit \\
\hline Male & $39 \%$ & $57 \%$ & $52 \%$ & $38 \%$ & $54 \%$ & $35 \%$ & $70 \%$ \\
\hline Female & 61 & 43 & 148 & 62 & 46 & 65 & 30 \\
\hline Ages 18-29 & 23 & 30 & 32 & 40 & 20 & 69 & 54 \\
\hline $30-49$ & 39 & 37 & 42 & 41 & 50 & 26 & 36 \\
\hline $50-64$ & 24 & 21 & $\square 18$ & 14 & 24 & 5 & 7 \\
\hline $65+$ & 15 & $\square 12$ & 18 & $\sqrt{5}$ & 6 & 1 & 12 \\
\hline High school or less & 38 & 40 & 28 & 36 & 16 & 44 & 26 \\
\hline Some college & 34 & 33 & 31 & 36 & 23 & 41 & 35 \\
\hline College+ & 28 & 27 & 41 & 28 & 61 & 15 & 40 \\
\hline White & 61 & 48 & 58 & 39 & 58 & 34 & 65 \\
\hline Nonwhite & 38 & 51 & 40 & 60 & 41 & 65 & 34 \\
\hline
\end{tabular}

Note: Tumblr, WhatsApp, TikTok and Twitch not shown. Nonwhite includes all racial and ethnic groups, except non-Hispanic white. Source: Survey of U.S. adults conducted July 8-21, 2019.

"Americans Are Wary of the Role Social Media Sites Play in Delivering the News" PEW RESEARCH CENTER

Figure 1 Profiles of social media news consumers in the U.S.[8]

Robin Dunbar, an anthropologist and evolutionary psychologist at the University of Oxford, put forward a theory. He believes that everyone can maintain contact with 150 acquaintances, but can only maintain close relationships of about 5 because our brains cannot handle them. There are more interpersonal relationships, and this data has remained the same in the history of mankind. Kyongdal Kim and others believe that social media fatigue is a negative evaluation of social media, including mental and physical fatigue after users have formed a variety of experiences in the process of using social media [2]. Human beings are creatures full of desire for new things, so they can quickly adapt to the ever-changing living environment, but such desire for new things can also lead to being kidnapped and manipulated by fresh news in social media. Therefore, too many social media messages will cause people to accept too many messages and fail to deal with every interpersonal relationship completely. Pendent on users, the higher the degree of social isolation that the Internet may produce. Therefore, college students should also pay attention to it. If they rely too much on social media, the more likely they are to be out of touch with social life, which will inevitably cause barriers and barriers to interpersonal communication. People will compare their real lives with the perfect lives that others deliberately create on social media such as Facebook, believing that other people's lives are rich and fulfilling and interesting, and then feel that their lives are very boring. This kind of comparison psychology is very easy to cause psychological imbalance, disappointment and anxiety in real life, and further deepen negative emotions.

\subsection{Causes Internet Violence}

Social media will cause online violence. The perpetrators will uncontrollably expand their violent tendencies and attack innocent people indiscriminately. The victims will be violated on their personal power and even cause mental illness. The violation of privacy is not only due to online violence, but every time social media is turned on, social media is guiding people's public opinion and cognition. "Interpersonal communication in the field of social media is different from the intricate interpersonal network in real life. In the virtual world constructed by the network, its safe and hidden characteristics satisfy people's psychological expression of real emotions and fear of being hurt." [3] Similarly, people will give up hiding their dark humanity on the Internet, thinking that they will not be responsible and will not be found when attacking other people on the Internet, so online violence has become a serious problem. For example, an innocent teacher who 
did not mistakenly believe that he was a cat abuser on the Internet, even though he repeatedly clarified that he was not the real cat abuser, no one was willing to stop the attack. In the end, he chose to commit suicide under the extreme cyber attack, and His family and friends were also attacked. The Mihara fire crater, one of the top ten suicide sites in the world, is located in Oshima, Oshima, Tokyo. A girl named Kiyoko was insulted by the world because she fell in love with her female classmate: "perverted" and "dirty" finally couldn't stand the torture of public opinion and jumped from the crater of Mount Mihara. According to the study on the lifestyle of netizens in the 24th Statistical Report on Internet Development in China published by the China Internet Network Center (CNNIC), the more heavily deCyber violence not only attacks innocent people verbally, but also seeks out the attacked people in real life, seriously infringing on the normal power and privacy of others. The terrible humanity displayed by people under the protection of the Internet can destroy a person's normal life, force him into mental problems and even choose to end his life. [4] Cyber violence not only attacks innocent people verbally, but also seeks out the attacked people in real life, seriously infringing on the normal power and privacy of others. The terrible humanity displayed by people under the protection of the Internet can destroy a person's normal life, force him into mental problems and even choose to end his life.

\subsection{Negative Effects on children's Development}

Social media will have a great impact on children in the growing period, impacting and controlling their outlook on life. Growing children do not have a complete outlook on life and self-awareness. Excessive exposure to the Internet and social media will absorb a lot of negative knowledge and guidance, leading to deviations in their growth. "Many children experience dramatic changes in early adolescence, although many children can use social media wisely. Excessive immersion in social media and the electronic world has become a key factor leading to a series of psychological problems such as addiction and depression, and teenagers are particularly vulnerable in this regard.[5]" For children, face-to-face communication and interaction cannot be replaced. The false sense of security brought about by social media cannot bring them normal social relationships and social skills. According to the General Health Questionnaire (GHQ), whether boys or girls, frequent use of social media is related to the occurrence of psychological distress. Among girls, the more frequently they check social media every day, the more likely they are to face psychological distress[6]. Early childhood experiences are important for the development of the brain areas responsible for social interaction, empathy, and other interpersonal skills. If there is a lack of interpersonal experience because of too much attention to electronic screens, this part of the child's brain will not be fully developed. Just as dopamine can stimulate diet and fertility, so endorphins released by contact seem to strengthen interpersonal bonds. Friendship and care on the Internet cannot replace face-to-face greetings and communication, and cannot build a complete social experience and ability for the growth of children.

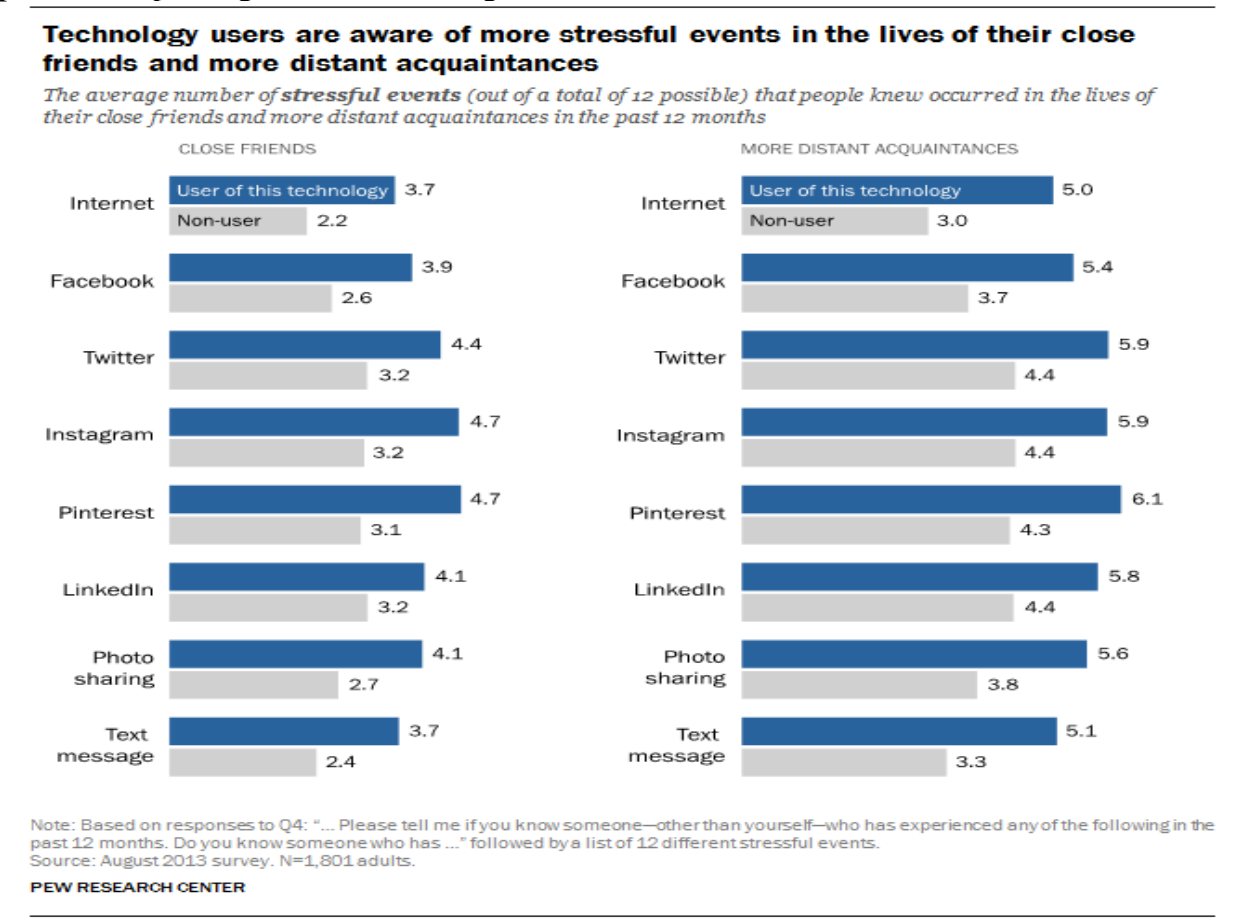

Figure 2 The General Health Questionnaire (GHQ)[6] 
In 2013, among the 13,000 children interviewed, the proportions of boys and girls who used social media multiple times a day were $43 \%$ and $51 \%$, respectively. This proportion increased to $51 \%$ and $68 \%$ respectively in 2014 and increased in 2015 To $69 \%$ and $75 \%$.

Dr. Linda Papadopoulos, as one of the most famous psychologists in the UK,joined Internet Matters as an ambassador and is always available to help parents protect their children online, "Keeping posted may also cause them to receive more negative or average reviews online instead of compliments or compliments. Maybe they may be more likely to experience cyberbullying, which is related to severe depression or even suicidal behavior in extreme cases.[7]" Similarly, cyberbullying may be more common among girls or may be more closely associated with psychological distress.

\section{CONCLUSION}

This thesis discusses research on the negative impact of social media on people's lives through negative emotional impact, online violence, and negative impact on children, using literature and case studies to draw the following conclusions. Social media can bring anxiety, stress, and social barriers to people, and such emotions can lead to a deeper social media addiction. People will believe in the deliberately faked perfect life shared on the Internet, and thus feel dissatisfied and anxious about their real life, and start to compare themselves with others. Cyber violence can destroy a person's life, violate a person's right to privacy, and cause many innocent people to be destroyed or even commit suicide. Excessive indulgence in the happiness and attention brought by the Internet and social media can cause social media addiction, social alienation, and the inability to communicate normally face-to-face. Children are more susceptible to influence when they come into contact with social media because they are at a stage where their outlook on life, world outlook and self-awareness have not developed and matured, making it impossible to distinguish whether information on the Internet is real or false. Since this thesis does not expand on more aspects of the negative effects of social media, such as for specific groups of people such as the working population, there is still a space for improvement in this thesis.

\section{ACKNOWLEDGMENTS}

I would like to thank my teachers and classmates who helped me in my dissertation research by providing valuable comments and suggestions, my classmates who helped me collect cases to give me richer ideas to revise and improve my dissertation, and my family and friends for their encouragement and support in my spirit and study.

\section{REFERENCES}

[1] Tarafdar, Monideepa, et al. "Explaining the Link between Technostress and Technology Addiction for Social Networking Sites: A Study of 'Distraction As a Coping Behavior." Information Systems Journal (2019)

[2] Kyongdal Kim, HyunJoo Kim \& Young Bae. Exploring the Concept and Determinants of SNS (Social Network Service) Fatigue[J]. Information and Social, 2013 (26) , 102-129.

[3] Xiao Jing.Human Alienation in the New Media Environment $[\mathrm{J}]$.Contemporary Communication,2007(5)

[4] China Internet Network Information Center (CNNIC). The 24th Statistical Report on Internet Development in China [EB/OL]. http://www.cnnic.cn/uploadfiles/doc/2009-07-16.

[5] Caldalas,Nicholas ,"Will social media destroy the next generation?" September 24, 2016, "Global Science" magazine

[6] The General Health Questionnaire (GHQ), Children's Physical and Mental Health Survey

[7] Dr. Papadopoulos, Linda, "How does social media affect the mental health of young people?" April 12th, 2017

[8] Larkin, Emilee, Reader Anxiety Up as News Intake on Social Media Surges ,October 2, 2019. http://www.courthousenews.com/reader-anxietyup-as-news-intake-on-social-media-surges/ 